\title{
Transatlantica
}

Revue d'études américaines. American Studies Journal

\section{Sylvia Le Bars. Le Conflit linguistique aux Etats-Unis.}

Rennes : Presses Universitaires de Rennes, 2001. 181p.

\section{Marc Deneire}

\section{CpenEdition}

Journals

Édition électronique

URL : http://journals.openedition.org/transatlantica/666

DOI : 10.4000/transatlantica.666

ISSN : $1765-2766$

Éditeur

AFEA

\section{Référence électronique}

Marc Deneire, «Sylvia Le Bars. Le Conflit linguistique aux Etats-Unis. », Transatlantica [En ligne], 1 | 2003, mis en ligne le 05 avril 2006, consulté le 29 avril 2021. URL : http://journals.openedition.org/

transatlantica/666 ; DOI : https://doi.org/10.4000/transatlantica.666

Ce document a été généré automatiquement le 29 avril 2021.

\section{(c) (i) $\odot$}

Transatlantica - Revue d'études américaines est mis à disposition selon les termes de la licence Creative Commons Attribution - Pas d'Utilisation Commerciale - Pas de Modification 4.0 International. 


\section{Sylvia Le Bars. Le Conflit linguistique aux Etats-Unis.}

Rennes : Presses Universitaires de Rennes, 2001. 181p.

\section{Marc Deneire}

1 Les questions linguistiques, que ce soit aux Etats-Unis ou en Europe, sont largement ignorées par les politologues et les civilisationistes, même si ceux-ci s'accordent sur le fait qu'elles jouent un rôle important dans la formation et la vie politique et sociale des états. Le livre de Sylvia Le Bars se révèlera donc particulièrement éclairant pour ceux et celles d'entre nous qui peinent à faire la part des choses entre les différentes positions énoncées dans la presse et la littérature spécialisée.

2 Selon Sylvia Le Bars, le conflit linguistique (et non les) se résume à une question fondamentale en ce début de siècle : l'anglais est-il menacé par l'espagnol aux EtatsUnis? Si ce n'est pas le cas, quels sont les enjeux d'un tel débat? Le Bars répond d'emblée à sa propre question en indiquant que les enjeux sont essentiellement politiques, voire idéologiques. Les défenseurs de l'anglais (les English-Only) estiment que toute reconnaissance des langues minoritaires menace la cohésion nationale. Il existe d'ailleurs des alliances avérées entre ceux-ci et la droite républicaine qui lutte pour un contrôle plus sévère de l'immigration, l'imposition des "valeurs américaines", la défense de leur propre statut, et qui s'expriment essentiellement à travers des organismes tels que Center for Equal Opportunity (CEO; Linda Chavez), l'Institute for Research in English Acquisition and Development (READ ; Rosaline Porter), et la National Review. Ceux-ci ont récemment remporté quelques victoires éclatantes, notamment en obtenant le vote des propositions 227 en Californie (1998) et 203 en Arizona (2000), propositions qui ont mis fin à plus de trente ans d'enseignement bilingue dans ces deux Etats. Parmi les défenseurs du bilinguisme et du biculturalisme (les English-Plus), on trouve la plupart des linguistes et des spécialistes de l'éducation qui, au delà des arguments de nature psychologique et pédagogique un peu trop rapidement traités dans le livre, considèrent le bilinguisme comme ressource, et le multiculturalisme comme vecteur de décloisonnement culturel et idéologique. Malheureusement, ces derniers n'ayant ni la puissance financière d'un Ron Unz, le sponsor des propositions 
227 et 203, ni l'expérience des campagnes politiques de leurs adversaires, n'ont pu efficacement défendre leurs arguments auprès du public lors du vote des propositions.

3 Ce débat permet à S. Le Bars de poser la question de l'identité et de la citoyenneté américaines. En effet, sous l'impulsion de l'évolution démographique récente, les questions d'intégration et d'assimilation se posent sous un jour nouveau. Au moment où près de la moitié des grandes villes américaines sont peuplées par une majorité de «non-blancs ", l'« accommodement » n'est plus synonyme de creuset, mais plutôt de partage de pouvoir entre les différents groupes linguistiques et ethniques. D'autre part, l'assimilation ne passe plus nécessairement par l'abandon de sa langue et de sa culture d'origine. C'est sur cette base que Le Bars propose l'adoption de nouveaux modèles, ceux de Hollinger, de Michael Lind et de Roberto Suro qui permettraient de dépasser les politiques identitaires.

4 Il s'agit donc de refondre la citoyenneté en terme de droits culturels et linguistiques, tout en évitant une (re-)ethnicisation par le biais de la langue, ce qui est, selon Le Bars, en train de se passer avec l'espagnol. Nous touchons là, nous dit Le Bars, à l'un des paradoxes produits par le contexte actuel; en effet, dans leur lutte pour la reconnaissance, les minorités se servent du système de racialisation et d'ethnicisation que la majorité a mis en place. Ce paradoxe peut mener à l'enfermement mais est également source d'espoir. On peut en effet espérer que la majorité prendra conscience de la fragilité de son appareil institutionnel et juridique et sera amenée à repenser sa politique vis-à-vis de ses citoyens dans toute leur diversité.

INDEX

Thèmes : Recensions

\section{AUTEUR}

MARC DENEIRE

Université Nancy 2 